\title{
Improvement in the Life of Cold Sinter Screen Decks of Sintering Plant by Using High Wear Resistant Hard-facing Alloys
}

\author{
M. Kalet, A. K. Bhakat \\ Steel Authority of India Limited (SAIL), Research \& Development Centre for Iron \& Steel (RDCIS), Ranchi, 834 002, India
}

\begin{abstract}
For smooth operation of the blast furnace, proper size and quality of the input raw materials are very much essential. Sinters produced in the sintering plants are first screened out to remove the undersize fractions before their supply to blast furnaces. The screens are fitted with punched steel deck plates where the undersized sinters are being screened. It was found that the life of these screen decks were very less due to its lower wear and abrasion resistance properties. So to imp rove the life and screening efficiency, high wear resistant hard-facing alloys was used over the base plate for use in the cold sinter screens. A layer of metallic carbides was deposited over the base plate to achieve higher hardness on the top surface. Simu ltaneously, the slots/ holes in the base plates were modified with increased taper across the thickness of the steel plates to overcome the problem of chocking/ b locking of holes during screening of sinter fines. The result showed about 4 times life improvement of the sinter screen decks i.e. 12 months from 3 months average. Moreover, $<5 \mathrm{~mm}$ size fraction of sinter in the blast furnace charge also reduced to $5 \%$ from mo re than $10 \%$ observed earlier.
\end{abstract}

Keywords Sinter, Screen Deck, Metallic Carbide, Wear, Hardfacing

\section{Introduction}

The low service life of sinter screen decks resulted in frequent shut down and replace ment that hampers production. The sinter screen deck plates made of high strength steels (YS > $350 \mathrm{MPa}$ ) were being worn out in every 3 months due to poor wear and abrasion resistance properties. The effect of hardness on wear behavior is one of the most important parameter that determines the service life of the components in tribosystems. Literature reveals that there are further developments in improving the wear properties of steel by using carbide coating on base metal. Wear is not an intrinsic material property but characteristics of the engineering system, which depend on load, speed, temperature, hardness, presence of foreign material and environmental conditions ${ }^{1-5}$. In this work to improve the life of deck plates a hard layer of coating material with suitable microstructure was deposited over the base plate. A layer ( $2 \mathrm{~mm}$ thick) of Cr-carbide alloy (hardness $\sim 500 \mathrm{BHN}$ ) over $10 \mathrm{~mm}$ thick mild steel plate was deposited. One set of decks so fabricated was put for industrial trial and monitoring carried out to find the life of decks.

For s mooth operation of the b last furnace, g ranulo metry of

* Corresponding author:

akbhakat@sail-rdcis.com (A. K. Bhakat)

Published online at http://journal.sapub.org/ijmee

Copyright (C) 2012 Scientific \& Academic Publishing. All Rights Reserved sinter plays a very important role in proper running of the blast furnace. Blast furnace needs sinter of size ranging from 5 to $80 \mathrm{~mm}$ for its efficient operation. Particu larly sinter fines $(<5 \mathrm{~mm})$ should be avoided in the skip charge to avoid choking of the furnace burden. So sinter produced in sinter plants are first screened out to remove the undersize fractions before their supply to blast furnaces. The screens are fitted with punched steel deck plates where the undersized sinters are being screened. These steel decks are generally made of high strength steels (YS > $350 \mathrm{MPa}$ ) and are of $12 \mathrm{~mm}$ thick. It was found that the life of these decks is less due to lower wear and abrasion resistance properties. As a result perforated slots made in the decks are getting enlarged and subsequently cracked in the edges leading to very low life of screen (3 months average).

So to imp rove the granulo metry and screening efficiency, high wear resistant hard-facing alloys was used over the base plate for use in the cold sinter screens. The literature reveals that metallic carbides are having high hardness as compared to alloys. So a layer of metallic carbides over the base plate was deposited to achieve higher hardness on the top surface. Simultaneously, the slots/ holes in the base plates were designed with increased taper across the thickness of the steel plates to overcome the problem of chocking/ blocking of holes during screening of sinter fines.

\section{Experimental}




\subsection{Wear Test of Cr-car bi de Hardfaced Steel Samples}

For its end use the abrasion tests were carried out in a dry sand abrasion-testing machine with different load and revolution of the wheel. Two types of mate rial ( $\mathrm{Cr}$ carb ide \& $\mathrm{Cr}$ boride) has been selected for wear testing and finalization of the alloy to be used in sinter screen decks. Testing was carried out as per ASTM G65-2004 (D) standard and the samples were prepared in the sizes of $12.7 \times 25.4 \times 76 \mathrm{~mm}$. This test characterizes materials in terms of weight loss under a controlled set of laboratory conditions. Correlation to actual field conditions may be influenced by other wear parameters such as the amount of impact, corrosion, galling, etc. Nevertheless, valuable insight into a materials field performance may be gained by examining the results of this test against a materia l's chemistry and microstructure. This is the criteria in which all materials used in abrasive wear applications should be subjected. This involves the abrading of a standard specimen with sand of controlled size and composition. The abrasive is introduced between the test specimen and a rotary wheel with a chlorobutyle rubber types or rim of a specified hardness. Load is being applied by means of a lever arm while a controlled flow of sand grit abrades the test surface. The rotation of the wheel is such that its contact does not face the direction of sand flow. The pivot axis of the lever arm lies within the plane which is approximately tangent to the rubber wheel surface and normal to the horizontal diameter along which load is applied. The rubber wheel (226 $\mathrm{mm}$ OD \& $12.7 \mathrm{~mm}$ wide rim) made of chlorobutyle rubber of hardness $60 \pm 2$ HRC. It is driven by a $2 \mathrm{HP}$ motor through a reduction gear box to get $200 \pm 10$ RPM at the rubber wheel. 4 Digital presentable electronic counter is used to stop test after preset revolution.

\subsection{Manufacture of Chromium Car bi de Coated Deck Plates}

After the selection of the economic wear resistant material the decks were fabricated and slots made as per the design. Blanks were cut from large mild steel plates (IS-2062 Gr. B) having thickness of $10 \mathrm{~mm}$ as per design. The top layer was restricted to $2 \mathrm{~mm}$ by deposition of iron based Cr-carbide alloy (C: $4.6 \%$, Si: $0.7 \%$, Mn: 1.0\%, Cr: $28 \%$ and balance $\mathrm{Fe}$ ) over the $10 \mathrm{~mm}$ mild steel plate by powder metallurgical diffusion process. The alloy powders of $\mathrm{Cr}$-carbide were fed through hopper at the tip of wire electrodes on the mild steel plate where the Cr-carbide powders were deposited to a thickness of $2 \mathrm{~mm}$ by fusion process. The required nos. of slots of desired geometry was cut in these plates with the help of plas ma cutting machine. In a set 27 no. of chromium carbide deposited punched steel deck plates were fabricated for the assembly of cold sinter screen. Afterwards the required angles and fixtures were welded to these deck plates. The photo of fabricated deck plate is shown in Fig-1. Blast Furnace $(\mathrm{BF})$ sinter samples were collected from this screen to analyze the percentage of undersize fraction $(<5 \mathrm{~mm})$ going to blast furnaces. Also plant return sinter samples were collected to find out the percentage of oversize fraction due to enlarged slots in the deck plates normally occurred due to abrasive wear.

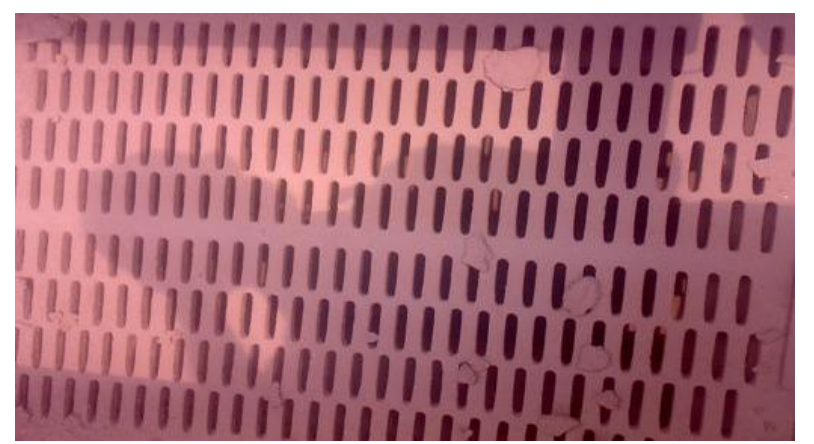

Figure 1. Deck of Cold sinter Screen fabricated using Cr-carbide hardfacing wear resistant alloy

\section{Results and Discussion}

Table 1. Wear loss data of chromium carbide coated sample

\begin{tabular}{|c|c|c|}
\hline $\begin{array}{c}\text { Distance traversed } \\
(\mathrm{m})\end{array}$ & $\begin{array}{c}\text { Wt loss (gm) } \\
\text { (Initialweight: } \\
\text { 127.022 gm) }\end{array}$ & Wear volume $\left(\mathrm{mm}^{3}\right)$ \\
\hline 107.44 & 0.148 & 19.47368 \\
\hline 214.88 & 0.235 & 30.92105 \\
\hline 322.32 & 0.302 & 39.73684 \\
\hline 429.76 & 0.366 & 48.15789 \\
\hline 537.21 & 0.479 & 63.02632 \\
\hline 644.65 & 0.496 & 65.26316 \\
\hline 752.09 & 0.508 & 66.84211 \\
\hline 859.53 & 0.566 & 74.47368 \\
\hline 966.98 & 0.595 & 78.28947 \\
\hline 1028.58 & 0.608 & 80.00000 \\
\hline 1136.02 & 0.614 & 80.78947 \\
\hline
\end{tabular}

Table 2. Wear loss data of chromium boride coated sample

\begin{tabular}{|c|c|c|}
\hline $\begin{array}{c}\text { Distance traversed } \\
(\mathrm{m})\end{array}$ & $\begin{array}{c}\text { Wt loss (gm) } \\
\text { (Initialweight: } \\
79.535 \mathrm{gm})\end{array}$ & $\begin{array}{c}\text { Wear volume } \\
\left(\mathrm{mm}^{3}\right)\end{array}$ \\
\hline 107.44 & 0.085 & 11.18421 \\
\hline 214.88 & 0.110 & 14.47368 \\
\hline 322.32 & 0.178 & 23.42105 \\
\hline 429.76 & 0.208 & 27.36842 \\
\hline 537.21 & 0.235 & 30.92105 \\
\hline 644.65 & 0.255 & 33.55263 \\
\hline 752.09 & 0.263 & 34.60526 \\
\hline 859.53 & 0.274 & 36.05263 \\
\hline 966.98 & 0.303 & 39.86842 \\
\hline 1028.58 & 0.310 & 40.78947 \\
\hline 1136.02 & 0.314 & 41.31579 \\
\hline
\end{tabular}


Table 3. Sieve analysis of sinter samples collected from BF and plant return conveyors

\begin{tabular}{|c|c|c|c|c|c|c|c|}
\hline \multirow{2}{*}{$\begin{array}{c}\text { Size } \\
\text { mm }\end{array}$} & \multicolumn{4}{|c|}{$\begin{array}{c}\text { Earlier decks } \\
\text { (SAILMA 350) }\end{array}$} & \multicolumn{3}{c|}{$\begin{array}{c}\text { New decks } \\
\text { (Chrome Carbide) }\end{array}$} \\
\cline { 2 - 9 } & \multicolumn{2}{|c|}{ BF SINTER } & \multicolumn{2}{|c|}{ PLANT RETURN } & \multicolumn{2}{c|}{ BF SINTER } & PLANT \\
RET URN
\end{tabular}

Wear test were conducted using sand as the abrasive media. Table-1 shows the wear test data conducted for $\mathrm{Cr}$ carbide coated steel plate whereas Table- 2 shows the wear test data for $\mathrm{Cr}$ boride coated plate. The wear loss data were plotted against the distance traversed for both $\mathrm{Cr}$ carbide \& Cr boride coated steel plates as shown in Fig. 2. It was found that wear loss of $\mathrm{Cr}$ boride samp les was almost half than that of $\mathrm{Cr}$ carbide coated samples. However, considering the economic advantages \& logistic approach, $\mathrm{Cr}$ carbide powder coating was selected for hardfacing in this application. Previously deck plates after about one week of use were getting choked and thereby needs intermediate cleaning for the screening of undersized material. However, due to the introduction of the non-clogging holes using precision cutting machine in the deck plates this problem has been entirely eliminated. This has been confirmed not only by visual inspection of the decks but also by the sieve analysis of BF sinter samples. The comparison of sieve analys is of both the deck materials has been given in Table-3. Two samples were collected in each case to validate the experimental results. Fro $m$ th is table it is very clear that the chromium carbide coated decks are performing very well compared to the uncoated deck materials. The undersize fraction was found to be less than $5 \%$ as compared to more than $10 \%$ observed earlier. Due to introduction of non-clogging holes the choking of ho les has been eliminated. Also the wear properties was found better due to higher hardness $(>550 \mathrm{BHN})$ of deck material and presence of sufficient percentage of carbides in the microstructure. The microstructure also confirms the presence of sufficient primary and secondary carbides in the matrix (Fig. 3). It is als o evident fro $\mathrm{mFig}$. 3 that the pres ence of primary carb ides is more prominent than smaller secondary carbides. These new coated decks will not only improve the life but also useful in efficient screening of undersize fraction in the sinter due to precision and non-clogging slots cutting. The service life achieved of the new deck was 12 months (4 times more) co mpared to uncoated deck material. The granulo mtry also showed a reduction of $50 \%$ i.e. $5 \%$ of $<5 \mathrm{~mm}$ size fraction of sinter from $10 \%$ obtained earlier in the blast furnace charge.

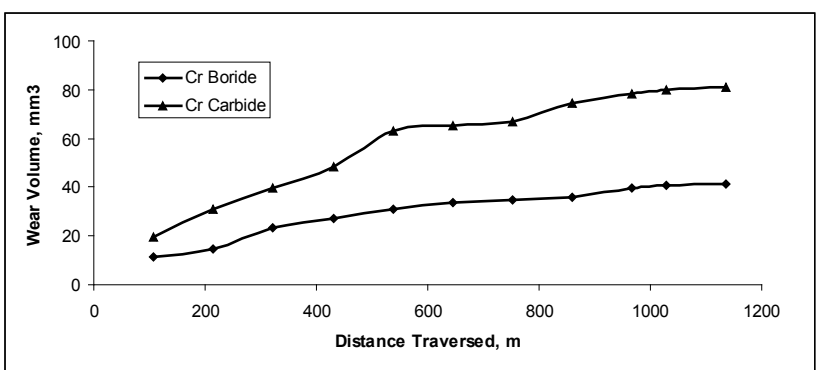

Figure 2. Wear test data of chromium boride \& chromium carbide coated sample

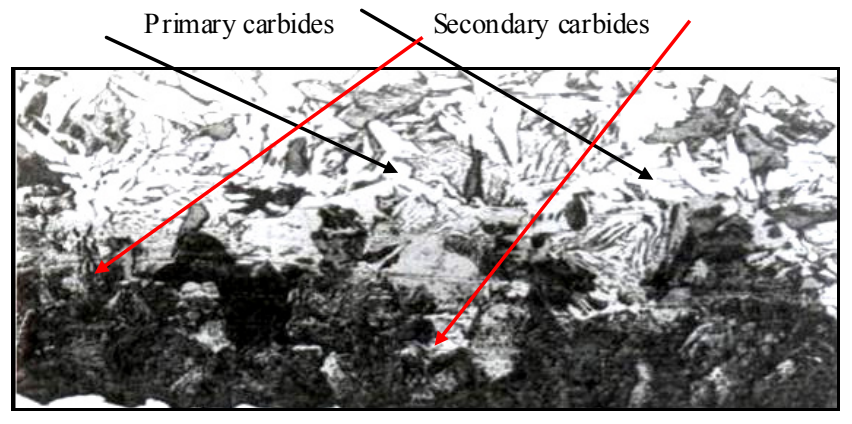

Figure 3. Micrograph of chromium carbide coated steel sample

\section{Conclusions}

- Both chromium carbide and chromium boride coated sinter screen decks are suitable for this application. However, considering the techno economics chromium carb ide coating was selected for industrial trial.

- Chromium carbide coated plates with slots fabricated as per design are more wear resistant due to its high hardness and presence of higher percentage of primary and secondary 
carbides the mic rostructure.

- Wear loss for Cr-carbide coated steel plates followed a linear relationship with sliding distance under present condition of testing.

- The screening of undersize fraction of sinter has been improved due to introduction of non-clogging types of holes in the cold sinter screen decks.

- The life of new decks achieved was 4 times more due to higher hardness and microstructural characteristics of the new identified hardfacing alloy.

\section{ACKNOWLEDGMENTS}

The authors wish to thank the management of Research \& Development Centre for Iron \& Steel, Ranchi for giving permission to publish this work.

\section{REFERENCES}

[1] D. A. Rigney, Sliding Wears of Metals, Annual Review Material Science, Vol. 18, (1988), 141-163.

[2] K. H. Zumgahr, Wear by Hard Particles, Tribology International 31 (1998) 587-596.

[3] J. Karger-Kocsis, A. Mousa, Z.Major, N. Bekesi, Dry friction and sliding wear of EPDM rubbers against steel as a function of carbon black content, Wear, Vol. 264, Issues 3-4, (2008), 359-367.

[4] D. F. Diao, Finite Element Analysis on Local Yield Map, Tribology International, Vol. 32, (1999), 25-32.

[5] K. Kato, Micro-mechanisms of Wear, Wear, 153 (1992), 277-295. 